$5-1999$

\title{
Slouching Towards Equality
}

Christopher J. Peters

University of Baltimore School of Law, cpeters@ubalt.edu

Follow this and additional works at: http://scholarworks.law.ubalt.edu/all_fac

Part of the Law and Philosophy Commons

\section{Recommended Citation}

Slouching Towards Equality, 84 Iowa L. Rev.801 (1999)

This Article is brought to you for free and open access by the Faculty Scholarship at ScholarWorks@University of Baltimore School of Law. It has been accepted for inclusion in All Faculty Scholarship by an authorized administrator of ScholarWorks@University of Baltimore School of Law. For more information, please contact snolan@ubalt.edu. 


\title{
SLOUCHING TOWARDS EQUALITY•
}

\author{
Christopher J. Peters ${ }^{* *}$
}

In Equality as Uncertainty, ${ }^{1}$ Joshua Sarnoff contributes helpfully to the ongoing (if intermittent) debate about the moral value of prescriptive equality and its implications for legal decisionmaking. But while Mr. Sarnoff's article fills some holes in our understanding of the impulse toward equal treatment, it also underscores the question that someone familiar with the recent legal-philosophical literature on the subject may be driven to ask: What's all the fuss about?

That question arises from the fact that recent contributions to the debate about prescriptive equality, including Mr. Sarnoff's, seem largely to agree on the central proposition that Peter Westen first articulated in his well-known 1982 article on the subject ${ }^{2}$ : Prescriptive equality is "empty," devoid of substantive moral content. My first goal in this brief reply to Mr. Sarnoff's article is to explain the source and extent of this agreement, with particular attention to the most recent law review commentaries-those of Mr. Sarnoff, Kent Greenawalt, ${ }^{3}$ and myself. Our agreement covers vastly more ground than our disagreements. Indeed, our disagreements center not on the validity of prescriptive equality itself, but on the propriety and coherence of nonegalitarian norms of justice that might sometimes require "equal" treatment.

My second goal will be to take up the most salient among these disagreements between Mr. Sarnoff and myself and to suggest some serious difficulties with Mr. Sarnoff's approaches to them. Mr. Sarnoff's "default" theory of prescriptive equality is of questionable efficacy even on its own terms. It also, and more importantly, is deeply self-contradictory in that it simultaneously relies upon and denies the necessity of moral judgment.

\section{WHAT'S ALL THE FUSS ABOUT?}

In 1982, Peter Westen argued that the idea of prescriptive equality-equality, that is, conceived of as a moral directive-is tautological and thus morally empty. ${ }^{4}$

*Copyright (C) 1999 Christopher J. Peters. With apologies to William Butler Yeats, The Second Coming (“And what rough beast, its hour come round at last/Slouches towards Bethlehem to be born?"), and ROBERT H. BORK, SLOUCHING TOWAROS GOMORRAH: MODERN LIBERALISM AND AMERICAN DECLINE (1996).

**Assistant Professor of Law, Wayne State University Law School. As always, I thank my wife, Trish Webster, for her patience.

1. Joshua D. Sarnoff, Equality as Uncertainty, 84 IowA L. REV. 377 (1999).

2. Peter Westen, The Empty Idea of Equality, 95 HARV. L. REV. 537 (1982). (1997).

3. Kent Greenawalt, "Prescriptive Equality": Two Steps Forward, 110 HARV. L. REv. 1265

4. The label "prescriptive equality" is, I believe, mine and not Professor Westen's. See Christo- 
Professor Westen defined prescriptive equality as "the proposition in law and morals that 'people who are alike should be treated alike' . . ." ${ }^{5} \mathrm{He}$ pointed out that nonegalitarian moral principles are necessary to identify "people who are alike" in this formula: "People who are alike" necessarily becomes "people who are identically entitled (by nonegalitarian principles) to be treated in a certain way." For example, two students, $X$ and $Y$, who both have scored $95 \%$ on a test are "alike" in that they are identically entitled to receive grades of $\mathrm{A}$ on the test.

Once the phrase "people who are alike" is filled out by the nonegalitarian criteria used to determine "likeness," the tautological quality of prescriptive equality becomes evident: "People who are alike should be treated alike" becomes the truism "people who are identically entitled (by nonegalitarian principles) to be treated in a certain way are identically entitled to be treated in that way." As applied to $X$ and $Y$, for example, prescriptive equality demands only the already obvious: Because $X$ and $Y$, by virtue of each having scored $95 \%$ on the test, are identically entitled to receive As, then $X$ and $Y$ are identically entitled to receive As. Prescriptive equality, Professor Westen concluded, is unavoidably tautological and thus meaningless as a moral directive.

The problem with Professor Westen's argument against prescriptive equality was that it overlooked the fullest expression of prescriptive equality, which is not in fact tautological. In two recent articles, ${ }^{6} I$ proposed a nontautological statement of prescriptive equality that I believe captures the normative force people often attribute to that principle. Prescriptive equality, I contended, is the principle that "people who are alike should be treated alike merely because they are alike"; or, as I phrased it in one article, "[i]dentically situated people are entitled to be treated identically merely because they are identically situated." Put differentlyviewed from an intermediate perspective, after one person already has been treated a certain way - prescriptive quality "is the principle that the bare fact that a person has been treated in a certain way is a reason in itself for treating another, identically situated person in the same way." 8

So stated, the principle of prescriptive equality is not tautological. After one fills out the criteria of "likeness" or "identical situation" using nonegalitarian norms, the principle of prescriptive equality provides yet another reason for equal treatment separate and apart from those nonegalitarian norms: the bare fact that the

pher J. Peters, Equality Revisited, 110 HARv. L. REV. 1210, 1211, 1215 (1997) [hereinafter Peters, Equality Revisited].

5. Westen, supra note 2, at 539 (citations omitted).

6. Peters, Equality Revisited, supra note 4, at 1222-27; Christopher J. Peters, Foolish Consistency: On Equality, Integrity, and Justice in Stare Decisis, 105 YALE L.J. 2031, 2062-64 (1996) [hereinafter Peters, Foolish Consistency].

7. Peters, Equality Revisited, supra note 4, at 1223.

8. Id. Kenneth W. Simons articulated a similar nontautological principle of prescriptive equality in Equality as a Comparative Right, 65 B. U. L. REV. 387 (1985), but did not attempt to debunk it as I did in Equality Revisited. 
people being treated are "alike" or "identically situated." As applied to the grading example, this nontautological principle of prescriptive equality tells us that students $X$ and $Y$, each of whom scored $95 \%$ on the test, are identically entitled to receive As not only because each scored $95 \%$, but also because each is identically situated to the other in the relevant respect. As such, giving student $\mathrm{X}$ an undeserved $\mathrm{A}+$ changes student $Y$ 's entitlement by giving us a reason (if not necessarily a decisive one) to give $Y$ an undeserved $A+$ as well.

I have argued at length that even this nontautological statement of prescriptive equality is either morally empty or morally incoherent. ${ }^{9}$ If we have valid reasons for wanting to give $\mathrm{Y}$ an undeserved $\mathrm{A}+$ after $\mathrm{X}$ has received one, they are reasons that have nothing to do with prescriptive equality-that is, reasons that do not rely upon the bare fact that two or more people are identically situated. Instead, they are reasons of nonegalitarian justice, which I have defined as the directive "that people be treated in accordance with the net effect of all the relevant (nonegalitarian) criteria and only the relevant (nonegalitarian) criteria." 10

As Mr. Sarnoff points out, this definition of nonegalitarian justice is heuristic, not substantive; it is "a formal cup of all nonegalitarian norms into which is poured 'an infinite variety of substantive moral conceptions of what criteria are "relevant" to a person's treatment in any given case." "Il In other words, my "nonegalitarian justice" encompasses, and stands as a placeholder for, any and every moral norm except norms of prescriptive equality (that is, norms that require equal treatment because of the bare fact of identical situation). In a previous article, Equality $R e$ visited, ${ }^{12}$ I attempted to demonstrate that one can trace every possible kind of (valid) reason for treating people "equally" solely to some conception of nonegalitarian justice rather than to prescriptive equality.

In a response to Equality Revisited, Kent Greenawalt contended "that the principle [of prescriptive equality] has force at least when two equals stand in some significant relationship to each other, and when the one who might receive worse treatment is aware that the other is an equal in relevant respects and has received better treatment." 14 This force, Professor Greenawalt asserted, stems from "the desirability of satisfying feelings of affected persons that unequal treatment is intrinsically unfair." 15 According to Professor Greenawalt, treating people equally is an "appropriate[] $\ldots$ respons[e]" to such "deep-rooted feelings," which are "not easily dispelled."

9. Peters, Equality Revisited, supra note 4, at 1231-57; Peters, Foolish Consistency, supra note 6, at $2065-73$.

10. ' Peters, Equality Revisited, supra note 4, at 1228.

11. Sarnoff, supra note 1, at 394 (quoting Peters, Equality Revisited, supra note 4, at 1229).

12. Peters, Equality Revisited, supra note 4.

13. Id. at 1231-57.

14. Greenawalt, supra note 3 , at 1266.

15. Id. at 1273 .

16. Id. 
Professor Greenawalt's defense of equal treatment, however, was not really a defense of the principle of prescriptive equality that I had attacked. Instead, it was an argument for treating people "equally" (or, at least, in ways perceived to be equal) for reasons of nonegalitarian justice-specifically the "appropriateness" of respecting people's "deep-rooted feelings" of unfairness when they suspect unequal treatment.

As Professor Greenawalt contended, equal treatment might indeed be an appropriate response to such feelings if undesirable consequences would result from not respecting them, consequences that outweigh any harm done by treating people wrongly in the name of equality. But this is not an argument of prescriptive equality, because it does not turn on the bare fact that the people involved are identically situated. (Indeed, it does not even require that the people involved are identically situated-only that one of them believes they are identically situated.) Only if the "deep-rooted feelings" of unfairness that counsel in favor of equal treatment can themselves be traced to valid norms of prescriptive equality is Professor Greenawalt's argument a defense of prescriptive equality rather than merely a justification for treating people "equally" for nonegalitarian reasons. But Professor Greenawalt did not purport to establish such a linkage (and indeed my article was an attempt to demonstrate that the linkage does not exist).

Professor Greenawalt, then, did not challenge the conclusion that prescriptive equality has no valid moral force of its own. Instead, he made the significant but different point that there may be good reasons of nonegalitarian justice for treating people equally. Mr. Sarnoff, in Equality as Uncertainty, appears to make the same general point, and to support it with a more extensive elaboration of essentially the same reasons for equal treatment suggested by Professor Greenawalt.

Mr. Sarnoff conceives of equal treatment as a hedge against the risk of incorrect moral judgment. Moral judgment will always be a matter of uncertainty, Mr. Sarnoff points out, because "substantive morality is 'epistemologically" or 'metaphysically' uncertain." know all the relevant [moral] criteria [for treatment] and how they should be applied" " ; the dictates of morality, even if they exist, are unknowable. Morality also may be metaphysically uncertain if "there simply is no objective standard to determine the relevant criteria of justice" 19 -that is, if objective morality does not in fact exist (a question whose answer is itself unknowable). "In either instance," $\mathrm{Mr}$. Sarnoff notes, "we cannot know whether and when we treat people justly in an absolute sense." 20

This fact of moral uncertainty, Mr. Sarnoff contends, makes it advisable to default to a rule of equal treatment in "situations where decisionmakers [do not]

17. Sarnoff, supra note 1 , at 384.

18. Id.

19. Id. at 385 .

20. Id. 
possess a high level of confidence in the morality of their judgmental criteria."21 Because equal treatment is a "theoretical commitment[] deeply rooted in Western culture,"22 unequal treatment often "appear[s] arbitrary" likely to suspect that it "may be the result of errors of judgment or the application of improper criteria." 24 Such suspicions, taken cumulatively, can have a damaging effect on the polity:

As the frequency of apparent errors increases or the apparent relevance of the criteria decreases, we become more likely to view our institutions as unjust and thus unfit to impose treatment. At its most corrosive, prescriptive equality [that is, the perception of unjustified unequal treatment] may induce civil disobedience to institutional decisionmaking. Prescriptive equality thus also has a destabilizing effect on our legal doctrines and our legal system. ${ }^{25}$

A default rule of equal treatment avoids or minimizes these undesirable effects by requiring "equal" (that is, the same) ${ }^{26}$ treatment of two or more seemingly similar people unless the decisionmaker "possess[es] a high level of confidence in the morality of [her] judgmental criteria" ${ }^{27}$ - unless, that is, the decisionmaker is reasonably sure that unequal treatment is the right thing to do. Defaulting to equal treatment in this way avoids the intuitive reaction against "unequal" treatment those disadvantaged by it are likely to experience. It thus also avoids the social harms that might arise if enough people come to believe that legal or political decisionmakers are regularly treating them unfairly.

In Part II, I discuss some troubling difficulties with this argument. For present purposes, however, it is enough to note that Mr. Sarnoff's defense of what he calls "prescriptive equality" 28 is not in fact a defense of that principle at all; rather, like Professor Greenawalt's, it is an argument in favor of equal treatment for nonegalitarian reasons. Indeed, one can view Mr. Sarnoff's analysis as a more deeply theorized version of Professor Greenawalt's argument.

Professor Greenawalt suggested that equal application of an incorrect treatment might be appropriate in certain circumstances as a response to deeply held

21. Id. at 381 .

22. Sarnoff, supra note 1 , at 390 .

23. Id. at 383 .

24. Id. at 382 .

25. Id.

26. Giving the same treatment to two people might not be seen as treating them "equally" if in fact the two people are not equally entitled to that treatment.

27. Sarnoff, supra note 1 , at 381 .

28. Mr. Samoff's definition of "prescriptive equality" is revealing: He "use[s] the phrase ... to refer to the normative demand for equal treatment, however expressed." Id. at 378-79 (emphasis added). "Prescriptive equality" for Mr. Samoff thus includes norms of nonegalitarian justice as I have defined it, see supra notes 10-11 and accompanying text, and is not limited to the directive that likes be treated alike merely because of their likeness. 
"feelings of affected persons that unequal treatment is intrinsically unfair," 29 feelings that "usually cannot be dispelled by "explanation." 30 Mr. Sarnoff provides a reason why such feelings often cannot be explained away: The fact of moral uncertainty prevents decisionmakers from demonstrating convincingly that the criteria upon which they base unequal treatment are morally correct. Those disadvantaged by unequal treatment will always have room to suspect that their disadvantage is "the result of errors of judgment or the application of improper criteria." 31 In other words, they will believe that they are being treated unjustly. This suspicion can be avoided only in "situations where decisionmakers possess a high level of confidence in the morality of their [decisions] ${ }^{, 32}$ (and where this confidence can convincingly be transposed to those bearing the brunt of unequal treatment).

This "default" theory of equal treatment is entirely a theory of nonegalitarian justice and not at all a theory of prescriptive equality as I have used that term. This is so for the same reasons that Professor Greenawalt's approach does not rely upon prescriptive equality. Placating people's feelings of unjustified "unequal" treatment often may be a good idea, to avoid adverse consequences like loss of respect for government and, eventually, civil disobedience. But this is not an egalitarian reason for equal treatment; it is not a reason grounded in the bare fact of likeness between or among two or more people. Again, only if one can trace the feelings being placated to valid norms of prescriptive equality is the conclusion of that principle's emptiness called into question. But Mr. Sarnoff, like Professor Greenawalt, does not provide such a connection, and does not attempt to provide one.

Like Professor Greenawalt, Mr. Sarnoff makes only an argument for equal treatment, not an argument for prescriptive equality. He does not provide reasons for treating people unjustly in order to treat them equally; instead, he provides an account of why the fact of moral uncertainty may change what it means to treat people justly. This is a thought-provoking argument, but it is not a defense of prescriptive equality.

What, then, is all the fuss about? Not much, if the subject of the fuss is prescriptive equality. Mr. Sarnoff, Professor Greenawalt, and I all seem to agree that prescriptive equality-the directive to treat likes alike merely because they are alike-has no moral validity. Mr. Sarnoff and Professor Greenawalt, however, offer reasons aside from prescriptive equality for requiring equal treatment. It is to these reasons that I now turn, focusing on Mr. Sarnoff's more extensive elucidation of them.

29. Greenawalt, supra note 3, at 1273 .

30. Id.

31. Sarnoff, supra note 1 , at 382.

32. Id. at 381. 


\section{EQUALITY AS A DEFAULT RULE}

As Part I explains, Mr. Sarnoff believes that the fact of moral uncertainty requires imposition of equal treatment as a default rule, operative unless a decisionmaker "posses[es] a high level of confidence in the morality of [her] judgmental criteria." ${ }^{33}$ Like all default rules, the requirement of equal treatment can also be seen as a presumption in favor of equal treatment, "var[ying] in direct proportion to the significance of our decisions, and in inverse proportion to our confidence in judgment." ${ }^{34}$ At some point, a decision becomes so insignificant, or the decisionmaker's confidence becomes so strong, or both, that the presumption against equal treatment is overcome. Short of that point, the decisionmaker must apply equal treatment.

There are two general categories of difficulty with this approach. First are lingering questions about whether defaulting to equal treatment, assuming the logical coherence of doing so, actually is likely to serve the salutary purposes Mr. Sarnoff attributes to it. Second is the incoherence of grounding equal treatment in the fact of moral uncertainty, and the implication of that incoherence: that moral uncertainty, while counseling humility in making judgments, cannot be a reason for refusing to make them.

\section{A. WHY EQUALITY?}

One might be tempted to ask why equal treatment is the default rule Mr. Sarnoff proposes in the absence of reasonable moral certainty. Why not unequal treatment? Why not treatment by coin-flip?

Mr. Sarnoff never exhaustively answers this question, perhaps because he thinks the answer is self-evident. But he at least suggests two kinds of answers, one that he defends at some length and another at which he only hints. I discuss each here in turn.

\section{The Argument from Effects}

As I suggest in Part I, Mr. Sarnoff's primary justification for defaulting to equality appears to turn on the "theoretical commitment" to equal treatment that is "deeply rooted in Western culture." 35 This cultural commitment to equal treatment triggers an intuitively negative reaction whenever two seemingly equal people are treated unequally; a suspicion arises that the unequal treatment is "the result of errors of judgment or the application of improper criteria." ${ }^{36}$ Because morality is

33. Id.

34. Id. at 380 .

35. Id. at 390. Mr. Sarnoff notes that "[o]ther cultures . . may not possess this commitment to equality and against arbitrariness, or may not adhere to it with equal force." Id. at 391 .

36. Sarnoff, supra note 1 , at 382 . 
inherently uncertain, such suspicions often cannot be satisfactorily explained away. The result can be "a destabilizing effect on our legal doctrines and our legal system." 37

The core problem with this analysis is that equal treatment may produce the same suspicions and feelings of resentment that unequal treatment may produceand indeed may pose further threats to the stability of the social order. Let me illustrate this point with an example from my own experience. ${ }^{38}$

In grading essay examinations in most of my law school courses, I use a rather complex system in which I specify the issues and arguments I want the students to address and assign a certain point value to each issue or argument. I also award extra credit for issues or arguments raised by students that I did not identify. After grading each essay question, I add up the student's total score using a spreadsheet program. When I have graded all the exams, I assign letter grades according to my law school's mandatory grading curve.

Obviously, there is a good deal of room for discretion, even error, in this grading process. Although the exams I grade are anonymous, I can never be sure that I gave the ninetieth student the same amount of credit for a particular issue that I gave the twentieth. I can never be sure that my standards for awarding extra credit are exactly the same for each student. I can never be sure that the cutoff point between A-minuses and B-pluses is the best one. Uncertainty lurks at every stage of the procedure.

Recognizing this uncertainty, I often agonize over the need to make fine distinctions between students. One student, $X$, has a total score of 90.00 out of 100 points; another, $Y$, has a total score of 89.75 . The 90.00 would be an A- on the curve, the 89.75 a B+. How can I differentiate between the two students on the strength, or weakness, of one quarter of a point? Perhaps I made an error in grading one or both of the two exams; perhaps I should have given $Y$ credit for an additional quarter of a point; perhaps I should not have given $X$ credit for that amount. Perhaps the line between an A- and a B+ is arbitrary and unfair. There are many grounds for lack of confidence in my judgment.

Faced with this uncertainty, I may be tempted simply to give both students the same grade. Note, however, the two ways in which I could accomplish this equal treatment. I could lower $X^{\prime} s$ grade to a B+, despite her apparent desert of an A-. Or I could raise $\mathrm{Y}^{\prime} \mathrm{s}$ grade to an $\mathrm{A}-$, despite his apparent desert of a $\mathrm{B}+$.

First, imagine what might happen if I choose the former alternative-lower-

37. Jd.

38. Mr. Sarnoff may be pleased to note that this example incorporates the fact of moral uncertainty rather than "assum[ing] away all uncertainty regarding the criteria for judgment" as I have done in previous examples. Id. Of course, Mr. Samoff's objection to "assuming away uncertainty" has force only if the fact of moral uncertainty coherently can generate an argument for equal treatment; as I explain below, it cannot. (In fact, even if moral uncertainty could generate an argument for equal treatment, it does not follow that moral uncertainty can generate an argument for prescriptive equality, which was the subject of the examples to which Mr. Sarnoff adverts.) 
ing $X^{\prime}$ 's grade to match $Y^{\prime}$ 's. If I do so, it is difficult to see how I have avoided the same sorts of negative reactions that might have been produced had I maintained the distinction between the two students. If $\mathrm{X}$ discovers that her grade has been lowered in the name of "equal treatment" with $Y$, she seems quite likely to protest that her revised grade is "the result of errors of judgment or the application of improper criteria." ${ }^{\text {"39 }}$ The same sense of justice that might be offended by differential treatment of the two students on the uneasy basis of a quarter-point difference surely will be offended-perhaps more so-by identical treatment of the same two students in the face of that difference.

The larger point here is that moral uncertainty not only implies the impossibility of conclusively demonstrating the correctness of moral judgments; it also implies the impossibility of conclusively demonstrating their incorrectness. As such, a person who is disadvantaged by a decisionmaker's reliance on a particular moral judgment, like $\mathrm{Y}$ if he gets a $\mathrm{B}+$ instead of an $\mathrm{A}-$, will always have grounds to complain that the basis of that judgment was incorrect, or at least not certain enough to support disadvantaging him. By the same token, a person who is disadvantaged by a decisionmaker's refusal to rely on a particular moral judgment, like $\mathrm{X}$ if her grade is lowered to a $\mathrm{Bt}$, will always have grounds to complain that the basis of that judgment was correct and thus should have been acted upon. The particular form of equal treatment that involves giving someone less than she deserves will produce the same grounds for complaint as unequal treatment.

What, then, if I choose the second alternative: raising $Y$ 's grade to match $X$ 's? Now X cannot complain that she did not get what she deserves. Or can she? Student $X$ 's grade of A- is rendered less valuable by the fact that $Y$ now has the same grade; grades, at least in classes with mandatory curves, are valuable as comparative rather than absolute measurements of achievement. The greater the number of students who receive A-minuses, the more diluted the value of each A-becomes. If every student got an A-, then there would be no point in having one. By awarding $\mathrm{Y}$ an undeserved A-, I will have harmed X's interest in preserving the full value of her deserved A-. X will have grounds for complaint after all.

One can generalize this point across instances of what I have called "conditions of competition" 4 - cases in which there is not enough of a particular good to go around. ${ }^{41}$ In such conditions, distributing goods (like prestigious grades) to those who do not deserve them in the name of "equal treatment" harms those who do deserve such goods by reducing the amount of goods available to them. Of

39. Id. at 382 .

40. Peters, Equality Revisited, supra note 4, at 1232.

41. Actually, I define "conditions of competition" in Peters, supra note 4, Equality Revisited, at 1232 as conditions in which there is not enough of a particular good to go around among those equally entitled to it. The definition usefully can be broadened for present purposes, however, to include conditions in which there is competition for scarce goods among anyone who wants them, whether or not the competitors are equally entitled to those goods. 
course, a decisionmaker may not be confident of her ability to distinguish between those who deserve a particular good and those who do not. But, again, the fact of this moral uncertainty gives $\mathrm{X}$ as much basis to complain about the dilution of her A- as Y has to complain about his B+. The "remedy" of equal treatment does not solve the problem of complaint.

It may be, of course, that not all treatment decisions involve competitive resources like the grading example does; in some cases there may be enough of a particular good for everybody, deserving or not. Let me suggest, however, that cases involving infinite resources will be relatively few and far between, and that the cases we care about most will almost always involve scarce resources of one form or another. If a resource is in infinite supply-like, perhaps, personal wellbeing or happiness ${ }^{42}$ - then we tend to assume that everyone has an equal entitlement to it, and we do not distinguish between or among people for purposes of distributing it. Only when there is not enough of a good to go around do we care about dividing it up, and about making distinctions that allow us to do so. If this is true, then in most cases achieving equal treatment by giving someone something he does not deserve will in fact give others grounds for complaint.

But there is an even more fundamental point lurking here. Suppose the addition of one more student to the ranks of the A-minuses will not appreciably dilute the value of X's grade. $\mathrm{X}$ still has grounds to complain about the raising of $Y$ 's grade-not for the reason that the two students have been treated equally, but for the reason that they have been treated unequally. $\mathrm{X}$, after all, has been given the grade that she (and I) believe she deserves; she has not been given the benefit of a boost to a higher grade. But $Y$ has been given this benefit-despite the complete lack of evidence that he is more entitled to it than $X$. $Y$ has been given a better grade than (I believe) he deserves; $X$ has not. The two students have been treated unequally, to X's detriment.

In other words, equal treatment of two people who may not deserve to be treated equally according to one standard necessarily amounts to unequal treatment of two people who may deserve to be treated equally according to another standard. If moral uncertainty demands equal treatment in one respect, how can it justify unequal treatment in another? This conundrum reflects the core difficulty with $\mathrm{Mr}$. Samoff's derivation of a presumption of equal treatment from the premise of moral uncertainty, and I discuss it further in section II.B.

There is yet another reason to question the efficacy of achieving equal treatment by giving people benefits they do not deserve: Doing so often causes other problems that may be no less threatening to the stability of the social order than perceived inequities in treatment. If my colleagues and I decide to compensate for the inherent uncertainty of our grading system and adopt a practice of giving eve-

42. To say that personal well-being is in "infinite supply" is not to say that everyone in the real world actually can obtain it-only that it is not logically impossible for everyone in the real world actually to obtain it. 
ryone the highest grade that our law school's rather loose grading policies will allow, several results may occur. One result will be the graduation, with decent grades, of some students who will not be competent lawyers. These lawyers' clients, and the legal system itself, will suffer for their incompetence. Perhaps worse, public perceptions of the effectiveness of the legal system will slowly be eroded as more and more incompetent lawyers find their way into practice. Even if few incompetent lawyers actually make it into practice, the public perception that "everyone gets As and Bs" in law school may lead to a conclusion of widespread incompetence. Some citizens will be inclined to take the law into their own hands, or to disobey the laws emanating from what they believe to be an ineffective system.

Farfetched? Perhaps, but no more so than the similar consequences Mr. Sarnoff warns may arise from widespread perceptions of unjustified unequal treatment. $^{43}$ If intuitive feelings of injustice may be triggered when seemingly equal people are treated unequally, then intuitive feelings of injustice also may be triggered when seemingly undeserving people are treated the same as seemingly deserving ones. Mere equality of treatment is no remedy.

\section{The Argument from Epistemic Asymmetry}

In Equality as Uncertainty, Mr. Sarnoff hints at another justification for defaulting to equality of treatment. He acknowledges that "imposing equal treatment may also be arbitrary and capricious by failing to make appropriate distinctions based on the relevant criteria or their proper application." ${ }^{, 44}$ However, he asserts, the fact of moral uncertainty means "[t]here is . . no countervailing force for prescriptive inequality." propriate.

Exactly what argument Mr. Sarnoff means to invoke by this conclusion is unclear; he does not go into more detail, and the only authority he cites is a large range of pages from a 1985 article by Kenneth Simons. ${ }^{46}$ Professor Simons's article suggests that Mr. Sarnoff may have in mind what I will call an argument from epistemic asymmetry.

At one point in the page range cited by Mr. Sarnoff, Professor Simons asserts:

[I]t is not surprising that, as Greenawalt concludes, "people usually feel a more acute resentment when those they deem equal are treated better than they are (e.g., given a higher salary) than when those they feel are relevantly less deserving are treated equally (e.g., given the same sal-

43. See Samoff, supra note 1 , at 382 ("At its most corrosive, prescriptive equality may induce civil disobedience to institutional decisionmaking."); id. at $398-400$ (discussing the risk of civil disobedience when widespread unequal treatment is perceived).

44. Id. at 389 (emphasis in original).

45. Id. (emphasis in original).

46. Id. at $389 \mathrm{nn} .39-40$ (citing Simons, supra note 8, at 437-59). 
ary)." It is much easier to conclude that another is roughly as deserving as you than to estimate how much less deserving he is. And if you are equally deserving, the prescribed treatment is simply equality of the relevant benefits. By contrast, even if you are confident that another is less deserving, you may not be confident about how much less he deserves. $^{47}$

If this is the passage Mr. Sarnoff means to invoke, then Mr. Sarnoff's argument here for default to equality of treatment is something like the following: It is epistemically easier to determine that, as a matter of nonegalitarian justice, two or more people are roughly equally entitled to a particular treatment than to determine exactly in what degree they are unequally entitled to that treatment. (For example, it is easier to conclude that two employees are both entitled to roughly the same salary than to determine exactly how much more one employee should be paid than the other.) In this way, equal treatment and unequal treatment are epistemically asymmetrical; it is easier to settle on a satisfactory equal treatment than on satisfactory unequal treatments. Thus the default rule in cases of uncertainty should be equality of treatment-which can be accomplished by simply giving each employee the same salary-rather than inequality of treatment, which requires the (epistemically more difficult) procedure of determining exactly how much more to pay one employee than the other.

This argument, however, is deficient on two levels. First, it is wrong as a matter of epistemology. I will stick with Professor Simons's (actually Professor Greenawalt's) salary example for the sake of consistency. Suppose a manager must determine what salary to pay each of two newly hired employees, $X$ and $Y$. Epistemically, it is no easier for the manager to determine that both employees are entitled to a salary of $\$ 50,000$, for example, than to determine that $\mathrm{X}$ is entitled to $\$ 60,000$ and $Y$ is entitled to $\$ 40,000$. In the cases of both $X$ and $Y$, the manager will have to independently perform the epistemic tasks of reviewing qualifications, assessing work experience, evaluating policies and precedents, etc. to determine the appropriate salary. It is not as if performing these tasks with respect to $\mathrm{X}$ gives the manager license to avoid performing them with respect to $Y$ and to simply give $Y$ the same salary by default. Nor is there something magical about arriving at the same salary figure for both employees that retroactively reduces the amount of epistemic work that was necessary to get there with respect to each of them.

It is true, of course, that the epistemic difficulty of the manager's task might be reduced if she decides beforehand simply to give both new employees the same salary. Then she can determine what one of them deserves and simply give them both that amount. But this is no better an argument for defaulting to equal treatment than it is for defaulting to treatment by coin-flip. Determining both employees'

47. Simons, supra note 8, at 443 (citing Kent Greenawalt, How Empty Is the Idea of Equality?, 83 COLUM. L. REV. 1167, 1175 (1983)). 
salaries completely at random would expend no epistemic effort at all; and yet it is fairly clear that neither Mr. Sarnoff nor Professor Simons would advocate random chance as the default decisionmaking mode in the face of epistemic difficulty. Nor, I suspect, would either of them claim that epistemic difficulty justifies always treating everybody the same with respect to every treatment-paying every employee the same salary, for instance, with no inquiry into desert, or giving the same welfare benefits to everyone who asks for them, without inquiring about need.

In short, the argument from epistemic asymmetry either proves too much, or it proves nothing at all. It proves too much if it holds that the difficulty of making a separate assessment of desert with respect to each individual justifies eschewing such an assessment altogether and simply always treating everyone the same-a remedy that no one reasonably could advocate. But without this kind of prescriptive force, the argument proves nothing at all, because the possibility of equal treatment cannot relieve the decisionmaker of the need to make a separate assessment of desert with respect to each individual.

The argument from epistemic asymmetry also is wrong in a second respect: It reflects two category errors, failing to distinguish between crucially different kinds, and between crucially different degrees, of epistemic moral uncertainty. The argument assumes a case in which a decisionmaker is epistemically uncertain not only about how two or more people should be treated differently, but about whether those people should be treated differently at all. For instance, the argument assumes that the manager not only is unsure about how much more to pay $X$ than $Y$, but even about whether $X$ deserves more money than $Y$ in the first place-or whether, instead, $\mathrm{X}$ and $\mathrm{Y}$ both deserve to be paid the same.

In fact, however, there will be many cases in which a decisionmaker is quite confident that two or more people deserve different treatment, but lacks confidence about exactly how their treatments should differ. For example, the manager might be confident that $X$ deserves a higher salary than $Y$ by virtue of her greater experience; but the manager might be unsure about how much more to pay X than $\mathrm{Y}$.

These two kinds of cases are crucially distinct. In the former kind of case, defaulting to equal treatment by paying $X$ and $Y$ the same salary will not clearly do injustice to either employee- because there are no clear grounds to argue that either employee is being paid more or less than he or she deserves. $\mathrm{X}$ cannot point to $\mathrm{Y}$ and say, "I know that I deserve a higher salary than he does (and I know that you, the manager, know this), and yet we are being paid the same. Either I'm getting less than I deserve, or $Y$ is getting more than he deserves." The epistemic uncertainty about whether the two employees are entitled to the same salary renders default to equal treatment unobjectionable.

In the latter kind of case, however, defaulting to equal treatment by paying $X$ and $Y$ the same salary clearly does injustice to at least one employee. Now $X$ can point to $Y$ and make her complaint: "I know that I deserve a higher salary than he does (and I know that you, the manager, know this), and yet we are being paid the 
same. Either I'm getting less than I deserve, or $\mathrm{Y}$ is getting more than he deserves." In this case, the existence of epistemic uncertainty does not preclude reasonable objections to default to equal treatment; the uncertainty goes to just how different the treatments of $X$ and $Y$ should be, not to whether they should be different at all.

The argument from epistemic uncertainty elides this second type of case, an omission subtly revealed in Professor Simon's statement "It is much easier to conclude that another is roughly as deserving as you than to estimate how much less deserving he is." 48 Even if this statement is true, it does not imply that it is always easier to conclude that another is roughly as deserving as you than to conclude that another is more or less deserving than you to some degree. In any case in which it is relatively "easy" to conclude-or, more accurately, in which there are reasonable grounds to believe and thus to argue-that one person deserves better treatment than another (even if the degree of "better" treatment is uncertain), defaulting to equal treatment will give that person cause to complain that an injustice has been done. In such a case, defaulting to equal treatment does nothing to avoid the undesirable effects that concern Mr. Sarnoff and that I discuss in section II.A.1.

As the foregoing discussion suggests, the argument from epistemic asymmetry also commits a second category error which compounds the first: failure to distinguish between different degrees of epistemic moral uncertainty. The argument assumes that the epistemic uncertainty facing the decisionmaker is complete-that the decisionmaker not only is ultimately uncertain about whether to treat two or more people differently, but has no valid grounds whatsoever upon which to base a decision to treat them differently. The decisionmaker is, in the vernacular of the day, utterly clueless. For instance, the argument assumes that the manager not only cannot decide whether $X$ should be paid more than $Y$, but does not even possess any valid indicia upon which to base such a decision-no employment histories, educational qualifications, personal attributes, or the like to compare (or, if these things exist, no grounds for determining that they make one employee more deserving than the other). There is, in short, nothing the manager can reasonably point to if required to justify a decision to pay $\mathrm{X}$ more than $\mathrm{Y}$.

In the real world, however, many (perhaps most) cases will be nothing like this. In many or most cases, there will be some reed, however slim, upon which to hang a decision to treat one person differently from another. In many or most cases, employee $\mathrm{X}$ will have slightly more work experience than employee $\mathrm{Y}$, or slightly better grades in school, or a slightly more winning personality. Of course, none of these differences may be sufficiently compelling to convince the manager that she is justified in paying $\mathrm{X}$ more than $\mathrm{Y}$. But the presence of reasons about which a decisionmaker is unsure is crucially different than the complete absence of reasons. As long as there is some reasonable basis for distinguishing between $\mathrm{X}$ and $\mathrm{Y}, \mathrm{X}$ will have grounds to complain if she is treated no better than $Y$. X, for instance,

48. Id. 
will be able to point to her higher grades in college and complain that she is being treated unjustly by being given the same salary as $Y$ (even though neither she nor the manager is certain whether she is being treated unjustly). Again, in such cases, defaulting to equal treatment fails to avoid the undesirable effects with which $\mathrm{Mr}$. Sarnoff is concerned. ${ }^{49}$

We are left, then, with what seems a fairly narrow category of cases in which the argument from epistemic asymmetry, even on its own terms, might have some sting: cases in which there are absolutely no reasonable grounds to determine whether one person should be treated better than another. In such cases, it does indeed seem reasonable to require that both people be treated the same. ${ }^{50}$ To describe this requirement as one of "defaulting to equality," however, or as a "presumption of equal treatment," would be to ignore causes and focus solely on effects-something like describing the survivors of the Titanic as having decided to tour the North Atlantic by lifeboat. In fact, the reason $\mathrm{X}$ and $\mathrm{Y}$ should be treated the same if there are no reasonable grounds to distinguish between them is that any differential treatment would, by definition, reflect one or more irrelevant criteria and thus would be wrong according to nonegalitarian justice. Equality of treatment is merely the byproduct of nonegalitarian justice - of treating each of $\mathrm{X}$ and $\mathrm{Y}$ as he or she deserves to be treated. ${ }^{51}$

\section{B. THE NECESSITY OF JUDGMENT}

Taken to its extreme, Mr. Sarnoff's argument from moral uncertainty proves far more than he, or anyone else, is likely to find palatable. Moral uncertainty infects every moral decision; it is not as if some moral precepts are objectively, conclusively knowable and others are not. The moral correctness of every judgment is open to question. If equal treatment is the appropriate response to moral uncertainty-if, as Mr. Sarnoff asserts, "prescriptive equality has force in all situations where moral judgment is required"

49. This kind of case - in which there are at least some reasonable grounds for treating one person better than another, despite uncertainty about those grounds-includes the exam grading example I introduced in section II.A.1, supra. In that example, the grader is epistemically uncertain about the validity and accuracy of his grading process, and thus about the validity and accuracy of giving the student with a 90.00 an $\mathrm{A}$ - and the student with an 89.75 only a B+. But because there are some reasonable grounds for treating the students differently, student $X$ with her 90.00 can complain about being treated unjustly if both she and student $Y$, with his 89.75 , are given the same grade. The presence of (partial) epistemic uncertainty does not eliminate the reasonable basis for complaint upon default to equal treatment.

50. Professor Simons seems to have this narrow category of cases in mind when he refers to a "presumption of equality"; he cites approvingly Professor Greenawalt's "suggest[ion] that a presumption of equality is appropriate when there are no reasons to treat persons unequally." Simons, supra note 8 , at 457 (emphasis altered). 57.

51. For a full explanation of why this is so, see Peters, Equality Revisited, supra note 4, at 1231-

52. Sarnoff, supra note 1 , at 380 . 
bility of distinguishing between or among people must always default to equal treatment. Equality of treatment becomes the universal, not just the default, rule.

This is not Mr. Sarnoff's conclusion, of course. Instead, Mr. Sarnoff postulates a "tipping point of confidence in judgment;" 53 prior to the tipping point (that is, when the decisionmaker's confidence in her judgment is not strong enough) the decisionmaker defaults to equal treatment, while beyond it (when her confidence in her judgment is strong enough) she may treat people "unequally." "The force of equality varies ... in inverse proportion to our confidence in judgment.",54

The salient characteristic of this "tipping point" solution is its paradoxical requirement of certain, or at least "confident," moral judgment. How is a decisionmaker to determine whether, and when, her moral judgment is certain enough to support unequal treatment? She can only make this determination by making a sort of "meta-judgment"- - a moral judgment about the certainty of her moral judgment. But if morality is inherently uncertain, how can the decisionmaker be confident in the accuracy of her meta-judgment about the accuracy of her first-order judgment? Must she make a third-order judgment-a meta-meta-judgment-about the accuracy of her meta-judgment? If so, how can she be confident in the accuracy of her third-order judgment? By making a fourth-order judgment? And so on. The problem is one of infinite regress.

The core difficulty of which this problem is a symptom is this: Once one proceeds from the fact of moral uncertainty to a presumption against exercising moral judgment, one has stopped playing the game of moral argument altogether. One has conceded that there are no rules by which that game can be played. Accordingly, one has estopped oneself from appealing to such nonexistent rules.

Mr. Sarnoff, however, frequently appeals to the rules of moral judgment that he claims do not exist. His reluctance to extend equal treatment to every case of decisionmaking uncertainty-that is, to every case-and his consequent invocation of a "tipping point" of moral certainty, with its inevitable moral judgment about moral judgments, is one example.

Another example is the very premise of his argument: that "equal" treatment is a coherent option in the absence of moral certainty. Here the problem lies in the fact that achieving equality of treatment requires making moral judgments about the relevant standards of "equality." Consider again the exam grading example. Moral uncertainty (of a sort) infects my judgment that student $Y$, with a score of 89.75 on his exam, deserves a $B+$ while student $X$, with a score of 90.00 , deserves an A-. If I decide to respond to this uncertainty by treating both students equally, however, I come up against the necessity of making new, similarly uncertain moral judgments. What amounts to "equal" treatment with respect to these two students? Is merely giving them the same grade sufficient to achieve "equality"? Or should I

53. Id. at 403 .

54. Id. at 380 . 
take other factors into account: for instance, the fact that student $Y$ has gotten straight As in all his other courses (thus making it unlikely that a single B+ will do him much harm) while student $X$ has gotten Cs in all her other courses (thus making her A- all the more important to her)? Should I account for the fact that $\mathrm{X}$ is independently wealthy (and thus doesn't really need a job in the legal profession) while $Y$ is laboring under the weight of tens of thousands of dollars in student loans? That $\mathrm{X}$ is a nicer person than $\mathrm{Y}$ ? That $\mathrm{Y}$ is a member of a minority group that is underrepresented in the legal profession?

Indeed, how do I know that $X$ and $Y$ are the students I should be comparing? Why not compare $X$ with $Z$, who scored 88.75? If I lack confidence in the moral correctness of giving a $\mathrm{B}+$ to $\mathrm{Y}$, with his $\mathbf{8 9 . 7 5}$, am I that much more confident that $\mathrm{Z}$ deserves a $\mathrm{B}+$ with a score that is only a point lower? Indeed, why not compare $\mathrm{X}$ with $\mathrm{W}$, who scored only a 66.50 but who, I happen to know from reliable sources, studied harder than anyone else in the class? Or with $\mathrm{V}$, who scored 70.00 but wants to become a public interest lawyer?

And suppose $\mathrm{I}$ settle on a comparison between $\mathrm{X}$ and $\mathrm{Y}$ and decide to raise $Y$ 's grade to an A-. I still am presented with the problem, mentioned in section II.A.l above, that treating $Y$ equally to $X$ with respect to his grade means treating him better than $\mathrm{X}$ with respect to the benefit of having his grade raised. Why is this inequality not the one I should worry about perpetrating? By the same token, why shouldn't I worry about treating $\mathrm{Y}$ unequally in comparison to $\mathrm{Z}$, whose $\mathrm{B}+$ has not been raised to an $\mathrm{A}-$ ?

The point of all this, of course, is that the decision to "default" to equal treatment is itself fraught with moral judgments. There is no more certainty with respect to these moral judgments than there is with respect to those supporting unequal treatment. Equality of treatment is no alternative to moral uncertainty; it is simply another vehicle for it.

Mr. Sarnoff's enterprise, then, is at war with itself. It can justify a presumption of equal treatment only as a response to the inherent uncertainty infecting nonegalitarian moral judgments. But the same uncertainty infects egalitarian moral judgments. We are left with no reason to prefer the (dubious) pursuit of equality over the (dubious) pursuit of other forms of justice.

\section{CONCLUSION}

Perhaps the most surprising feature of Mr. Sarnoff's article Equality as Uncertainty is that, despite its billing, it is not about prescriptive equality at all. Mr. Sarnoff does not argue that prescriptive equality-the command to treat likes alike merely because they are alike-has any substantive moral force. Instead, he argues that there are other reasons, nonegalitarian reasons, for a presumption of equal treatment. 
But Mr. Sarnoff's other reasons collapse into themselves. Moral uncertainty cannot be a reason for equal treatment, because moral uncertainty pervades attempts to achieve equal treatment just as it suffuses attempts to justify unequal treatment. If nonegalitarian justice is uncertain, equality is no less so.

There is a message here, I think. The message is that moral judgment is inevitable, even-perhaps especially -in a world of moral uncertainty. If the dictates of morality were written down somewhere, morality would be simply a matter of interpretation, and we might be justifiably reluctant to act without tracing our actions directly to the letter of the moral law. But morality is not written down, and so we are denied the luxury of deferring to some universal text. Instead, we have to make moral judgments as best we can-humbled but not deterred by the recognition of our own fallibility.

If so, equal treatment is not an alternative to the exercise of moral judgment. It is a function of that exercise, just as unequal treatment is. No purpose is served by slouching towards equality reluctantly, as if there were no other choice. Better to stride there firmly, or to stride firmly in the other direction. 